\title{
Influence of the $\mathrm{w} / \mathrm{c}$ ratio and aggregate composition on the autogenous shrinkage in self-consolidating concrete
}

\author{
Adam Zielinski ${ }^{1, *}$, and Maria Kaszynska $^{1}$ \\ ${ }^{1}$ Faculty of Civil Engineering and Architecture, West Pomeranian University of Technology, \\ Piastów 50, Szczecin, Poland
}

\begin{abstract}
Paper presents the analysis of shrinkage development in selfconsolidating concretes (SCC). Concretes were cured for 28 day in an insulated environment. The shrinkage was tested on $35 \times 150 \times 1150 \mathrm{~mm}$ samples. The specimen had the same volume as ring specimen proposed in the ASTM method of testing the susceptibility of concretes to cracking caused by the restricted radial shrinkage. Linear deformation of concrete samples was measured in constant periods of $500 \mathrm{~s}$ using dial gauges with digital data loggers. Conducted tests showed the influence of w/c ratio of $0.28,0.34,0.42$ and aggregate composition on the development of the autogenous shrinkage in self-consolidating concretes. Additionally, rheological properties of the concrete mixes were tested and compressive and splitting strength was determined. Conducted research allowed to evaluate the influence of $\mathrm{w} / \mathrm{c}$ ratio and natural aggregate composition on the development of autogenous shrinkage in different stages of curing of SCC.
\end{abstract}

\section{Introduction}

The early age cracking of High-Performance Concretes (HPC) is a result of increasing internal stresses caused by the restraining free deformation of the element. Deformation can be limited by various internal and external factors. External factors include: surrounding formwork, casting on existing, rigid structure or improper expansion joints. Internal stresses are mostly caused by the improper rebar deployment or concrete mix design, including the water-cement ratio, non-deformable natural aggregate and high cement amount [1].

Autogenous shrinkage of concrete is a dangerous phenomenon, especially for flat structural elements such as bridge slabs, floors and walls. Use of the High Performance Self-Consolidating Concretes (HPSCC) with $w / c<0.4$ speeds up the construction process, simultaneously improving the strength and durability [2,3]. However, such elements exhibit unintentional cracking. The cause of the cracking of concrete slabs lies not in the hydration heat or expansion factors, but in the simultaneous action of two shrinkages - drying and autogenous. In case of the flat concrete elements with a high surface area, the drying shrinkage will also cause higher deformation. Drying shrinkage is reversible and its effect

\footnotetext{
*Corresponding author: adam.zielinski@zut.edu.pl
} 
can be minimized with a proper external curing. In case of the autogenous shrinkage, which is irreversible, the external curing does not significantly improve the condition of the element. There are several methods of the internal curing that can limit the autogenous shrinkage $[4,5]$. One of the most basic methods is to increase the $\mathrm{w} / \mathrm{c}$ ratio.

The article presents the analysis of the influence of the water-cement and wateraggregate ratios on the autogenous shrinkage of cement composites with constant binder composition. The analysis of the shrinkage development was performed after 1 and 28 days. Mixes used in the study exhibited similar rheological properties and were analyzed based on their material ratios. Rheological properties were acquired with use of a superplasticizer.

\section{Mixture proportions and specimen}

The study was performed on four Self-Consolidating mixes. Half of the mixes were made using only fine natural aggregate, the other using fine and coarse natural aggregates. Three mixes had water-cement ratio of $w / c<0.35$ that is usually found in HPC. The fourth concrete had $\mathrm{w} / \mathrm{c}=0.42$, typical for ordinary concretes. The latter was used as a reference for evaluation of the autogenous shrinkage in HPC.

Authors used Portland Cement CEM I 42.5 R, mineral additives of fly ash and silica ash and superplasticizer. The amount of mineral additives in the mixes is constant in relation to cement mass. The superplasticizer was added in amount between $0.5 \%$ and $2.5 \%$ to maintain the assumed consistency. Mix designs are shown in Table 1.

Table 1. The mix design.

\begin{tabular}{|c|c|c|c|c|c|c|c|}
\hline \multirow{3}{*}{ Mix } & \multirow{3}{*}{$\begin{array}{l}\text { Cement } \\
{\left[\mathrm{kg} / \mathrm{m}^{3}\right]}\end{array}$} & \multicolumn{2}{|c|}{$\mathrm{SCM}\left[\mathrm{kg} / \mathrm{m}^{3}\right]$} & \multirow{3}{*}{$\begin{array}{l}\text { Water } \\
{\left[\mathrm{kg} / \mathrm{m}^{3}\right]}\end{array}$} & \multirow{3}{*}{$\begin{array}{c}\mathrm{SP} \\
{\left[\mathrm{kg} / \mathrm{m}^{3}\right]}\end{array}$} & \multirow{2}{*}{\multicolumn{2}{|c|}{$\begin{array}{c}\text { Natural aggregate } \\
\qquad\left[\mathrm{kg} / \mathrm{m}^{3}\right]\end{array}$}} \\
\hline & & \multirow{2}{*}{$\begin{array}{l}\text { Fly } \\
\text { Ash }\end{array}$} & \multirow{2}{*}{$\begin{array}{l}\text { Silica } \\
\text { Fume }\end{array}$} & & & & \\
\hline & & & & & & $0-2 \mathrm{~mm}$ & $2-8 \mathrm{~mm}$ \\
\hline M-1 & & 116 & 61 & 30 & 3.4 & 1004 & - \\
\hline M-2 & & 127 & & & 18 & 110 & - \\
\hline M-3 & & 72 & 38 & & 8 & 624 & 1072 \\
\hline M-4 & 458 & 73 & 39 & 128 & 11.5 & 636 & 1092 \\
\hline
\end{tabular}

Table 2 presents the material ratios in prepared mixes: water-cement, water-binder, cement-aggregate and binder/aggregate.

The autogenous shrinkage of prepared concretes was measured in a test bench of own design. The test bench was situated in a climatic room with constant environmental conditions of $\mathrm{T}=20^{\circ} \mathrm{C} \pm 2{ }^{\circ} \mathrm{C}$ and $\mathrm{RH}=50 \% \pm 5 \%$. Three slab samples $35 \times 150 \times 1150 \mathrm{~mm}$ were made from each mix. The volume of the samples was equal to the volume of the ring samples proposed by the ASTM C 1581-16. The displacement was measured with digital gauges on both ends of the insulated samples. The deformation was registered every $500 \mathrm{~s}$ and recorded in a database.

Table 2. Material ratios of studied mixes.

\begin{tabular}{|c|c|c|c|c|}
\hline Mix & $\begin{array}{c}\mathrm{w} / \mathrm{c} \\
{[-]}\end{array}$ & $\begin{array}{c}\mathrm{w} / \mathrm{b} \\
{[-]}\end{array}$ & $\begin{array}{c}\mathrm{c} / \mathrm{a} \\
{[-]}\end{array}$ & $\begin{array}{c}\mathrm{b} / \mathrm{a} \\
{[-]}\end{array}$ \\
\hline $\mathrm{M}-1$ & 0.42 & 0.338 & 0.722 & 0.898 \\
\hline $\mathrm{M}-2$ & 0.28 & 0.225 & 0.722 & 0.898 \\
\hline M-3 & 0.34 & 0.28 & 0.265 & 0.330 \\
\hline M-4 & 0.28 & 0.225 & 0.265 & 0.330 \\
\hline
\end{tabular}

Four times longer samples as in the ASTM C 1698-09, high precision of the gauges and short measuring intervals allowed to determine the development of the autogenous 
shrinkage. The test allowed to precisely determine the inflection points on the shrinkage development curve in the first 24 hours. Stable surrounding conditions and automatic measurement constituted to the low standard deviation of the values of autogenous shrinkage in concrete samples. Figure 1 presents the test bench during the shrinkage test of M-1 mix.

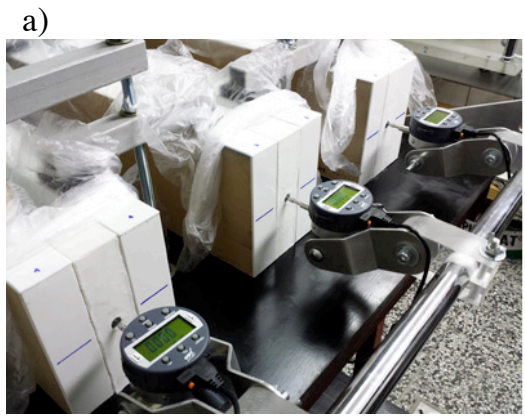

b)

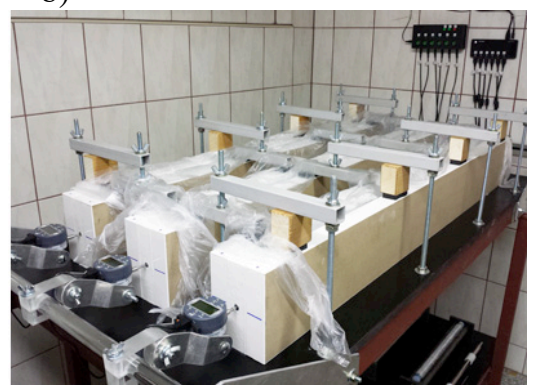

Fig. 1 Test bench for registration of linear shrinkage: a) dial gauges, b) general view

\section{Test results and discussion}

The first step was to obtain the assumed consistency in rheological tests. In case of insufficient flowability of the mix, additional amounts of the superplasticizer were added. Moulds 10x10x10 cm were casted to acquire samples for strength tests. Prepared mix was then taken to the climatic chamber and casted into the test site.

\subsection{Rheological and strength properties}

The evaluation of self-consolidating properties was made based on the Slum Flow test in accordance with EN 12350-8 - for mixes with fine and coarse aggregate; in accordance with [6] for mixes with fine aggregate only. The study assumed the slump flow between $600-750 \mathrm{~mm}$ for mixtures with fine and coarse aggregate and $240-260 \mathrm{~mm}$ for mix with fine aggregate only. Additionally, in accordance with ACI 237R-07 authors evaluated the resistance to segregation using Visual Stability Index (VSI). Results of the rheological and strength tests are visible in Table 3.

Table 3. Rheological and strength properties

\begin{tabular}{|c|c|c|c|c|}
\hline $\begin{array}{c}\text { Mix / } \\
\text { Composite }\end{array}$ & M-1 & M-2 & M-3 & M-4 \\
\hline $\begin{array}{c}\text { Slump-flow, } \\
\mathrm{D}_{\max }[\mathrm{mm}]\end{array}$ & 250 & 260 & 720 & 610 \\
\hline $\begin{array}{c}\text { Visual Stability } \\
\text { Index }\end{array}$ & VSI0 & VSI0 & VSI0 & VSI0 \\
\hline $\begin{array}{c}\text { Compressive } \\
\text { strength (28 d.) } \\
f_{\text {c, } 10 \times 10}[\mathrm{MPa}]\end{array}$ & 65.2 & 102.9 & 99.6 & 100.5 \\
\hline $\begin{array}{c}\text { Splitting tensile } \\
\text { strength (28 d.) } \\
f_{\text {ct,sp }}[\mathrm{MPa}]\end{array}$ & 4.47 & 4.73 & 4.51 & 5.21 \\
\hline
\end{tabular}




\subsection{Free linear autogenous shrinkage test}

\subsubsection{Water/cement ratio}

The influence of the w/c ratio on the development and values of the autogenous deformation was studied for all mixes.

Figure 2 presents the development of autogenous deformation in M-1 and M-2 mixes during the first 24 hours. Figure 3 presents the shrinkage development in the same mixes in a longer, 28-day period. Figure 4 shows the daily development of autogenous shrinkage as percentage of the overall shrinkage after 28 days.

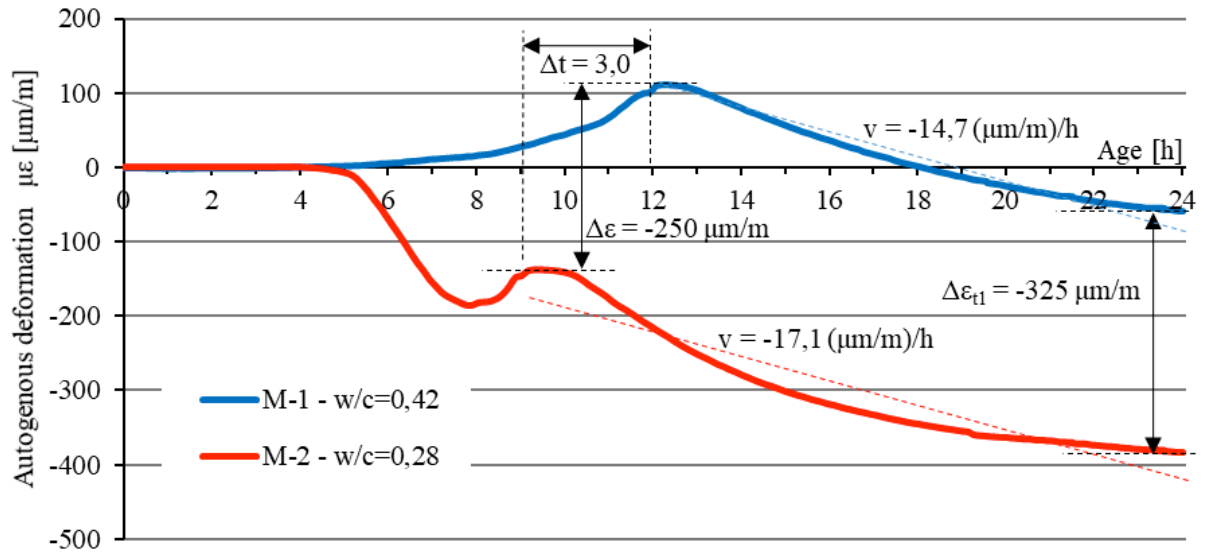

Fig. 2 The influence of the w/c ratio on the value of autogenous deformation of M-1 and M-2 composites in the first $24 \mathrm{~h}$

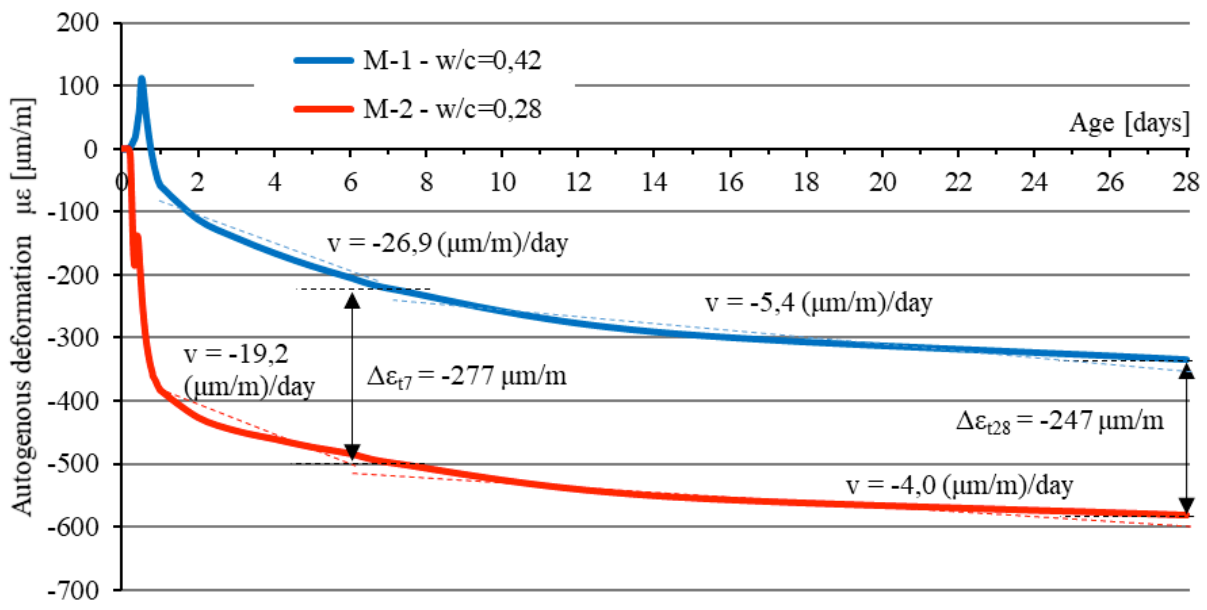

Fig. 3 The influence of the w/c ratio on the value of autogenous deformation of M-1 and M-2 composites during 28 days 


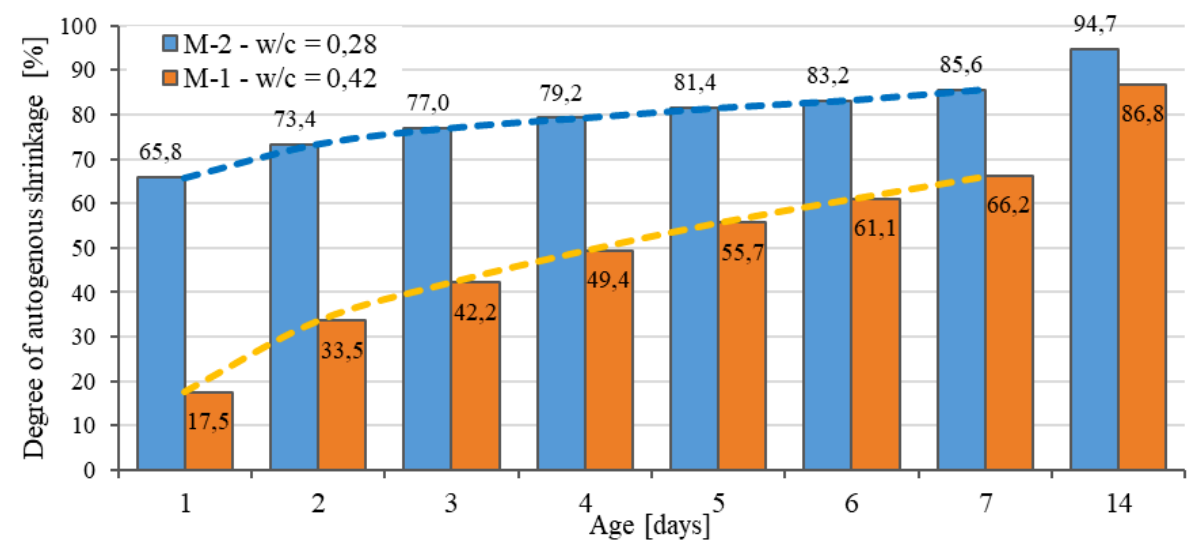

Fig. 4 Daily development of autogenous shrinkage as percentage of the overall shrinkage after 28 days

Following conclusions can be drawn from the aforementioned Figures:

- The reduction of the w/c ratio from 0.42 to 0.28 changed the mechanism behind the development of autogenous deformation. The M-1 composite exhibited swelling, while M-2 exhibit autogenous shrinkage. Reduction of the w/c ratio to 0.28 causes a shortage in mixing water;

- Increase of the w/c ratio causes increment of the autogenous shrinkage by about $15 \%$ after a day, $55 \%$ after 7 days and $40 \%$ after 28 days comparing to composite with the lower w/c ratio;

- Reduction of the w/c ratio from 0.42 to 0.28 affects the development speed of the autogenous shrinkage. Composite with the lower w/c has higher rate by about $16 \%$ in the first 24 hours, but exhibit lower rate during the next 6 days by about $40 \%$. Between $7^{\text {th }}$ and $28^{\text {th }}$ day shrinkage development rate for the composite with higher w/c ratio is higher by about $30 \%$.

Figure 5 presents the development of the autogenous deformation in M-3 and M-4 mixes during the first 24 hours. Figure 6 presents the shrinkage development in the same mixes in a longer, 28-day period. Figure 7 shows the daily development of the autogenous shrinkage as percentage of the overall shrinkage after 28 days.

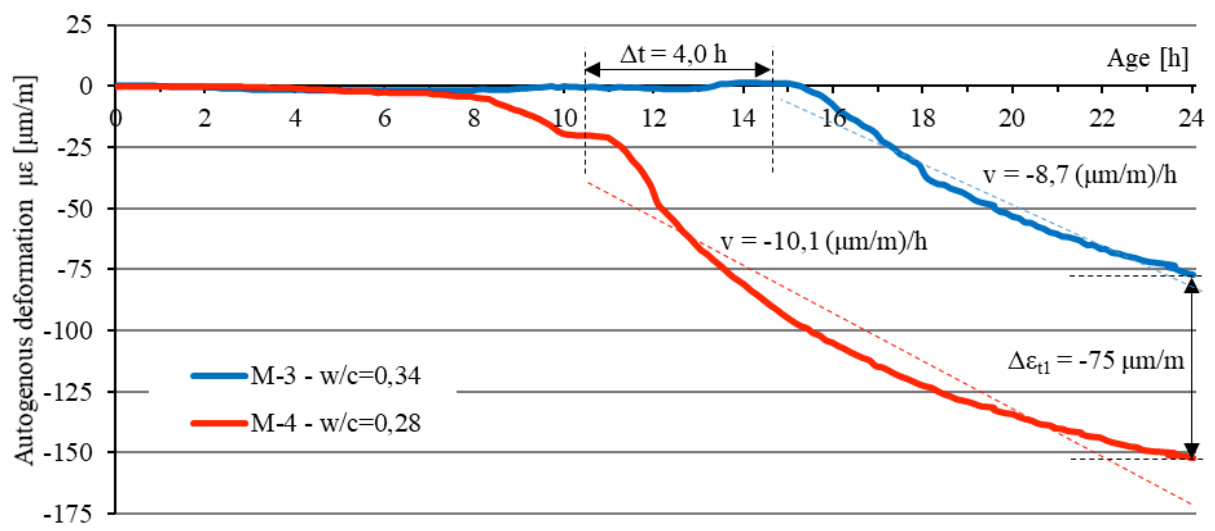

Fig. 5 Autogenous deformation of M-3 and M-4 composites in the first $24 \mathrm{~h}$ 


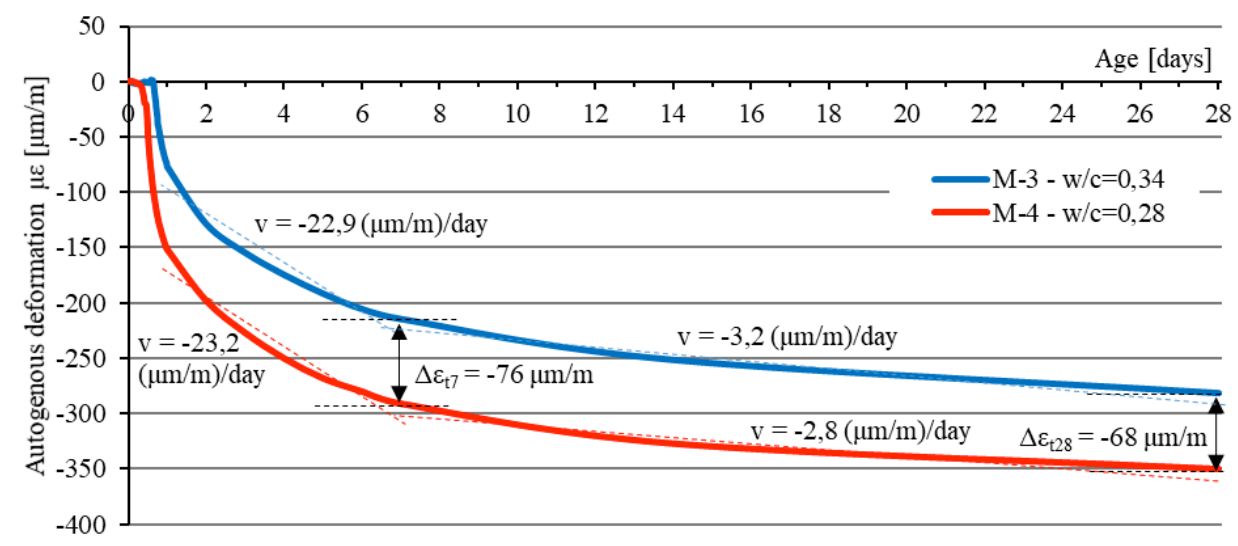

Fig. 6 Autogenous deformation of M-3 and M-4 composites during 28 days

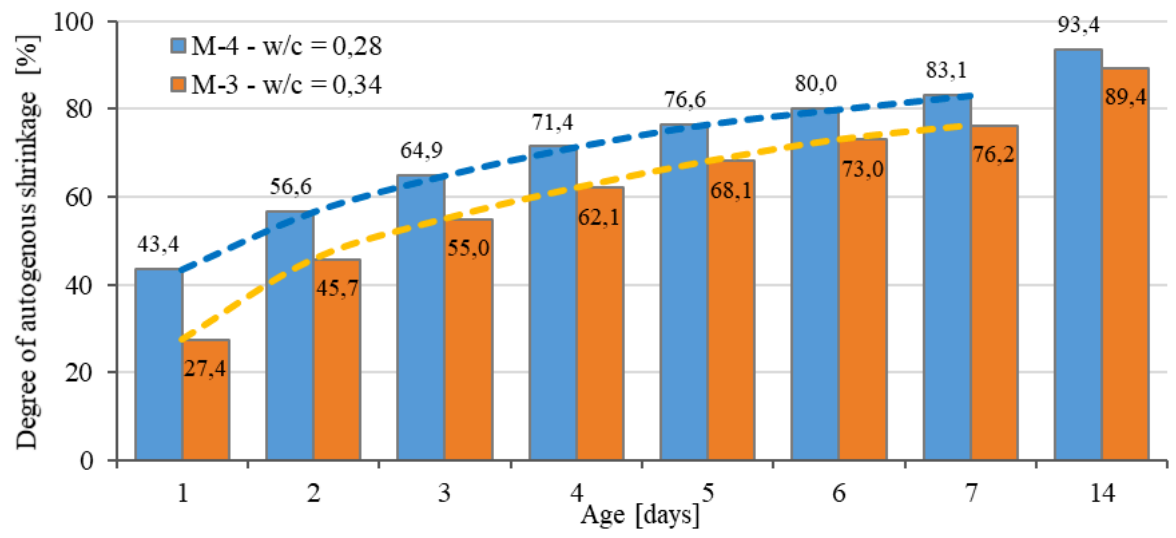

Fig. 7 Daily development of autogenous shrinkage as percentage of the overall shrinkage after 28 days

Following conclusions can be drawn from the aforementioned Figures:

- Reducing the w/c ratio from 0.34 to 0.28 caused the autogenous shrinkage value to rise by about $50 \%$ after a day, $25 \%$ after 7 days and $20 \%$ after 28 days;

- Reducing the w/c ratio from 0.34 to 0.28 increased the development rate of the autogenous shrinkage by $14 \%$ in the first 24 hours. The difference in the development rate however decreases to about $1 \%$ during following 6 days. After 7 days higher shrinkage development rate $(12 \%)$ was visible in a concrete with higher w/c;

- Autogenous shrinkage of M-4 composite begins to develop just after water-cement contact, while in M-3 only after hardening.

Presented analysis shows that the composites with lower w/c ratio have higher autogenous shrinkage which develops at higher rate in the first 24 hours. However, during the hardening phase the development slows down and begins to stabilize. In case of concretes with higher water content, in the first 24 hours the value of autogenous shrinkage is lower, but its development rate during hardening phase is higher.

The development of the autogenous shrinkage in composites with the higher w/c ratio is slower but progresses for a longer time up till the later stages of hardening. The effect is 
caused by the increased amount and size of the capillary pores. Composites are thus more susceptible to volume changes during the hardening.

\subsubsection{Aggregate composition}

The analysis of the influence of the aggregate composition on the development and value of autogenous deformation was conducted on M-2 and M-4 composites with w/c ratio of 0.28 . The composites had respectively cement-aggregate ratios of 0.722 and 0.265 .

Figure 8 presents the development of the autogenous deformation in M-3 and M-4 mixes during the first 24 hours. Figure 9 presents the shrinkage development in the same mixes during a longer, 28-day period. Figure 10 shows the daily development of autogenous shrinkage as percentage of the overall shrinkage after 28 days.

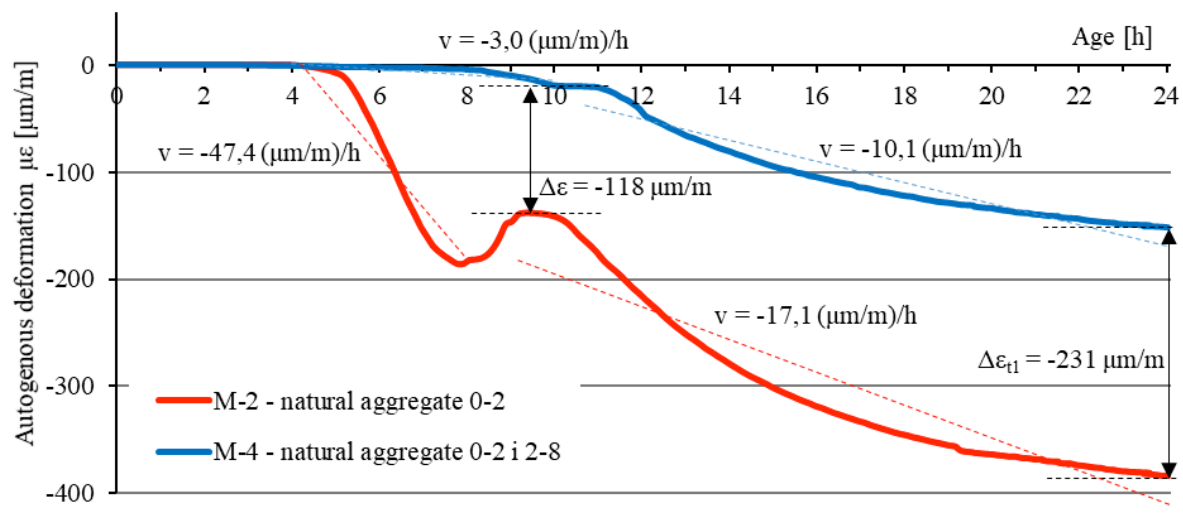

Fig. 8 Autogenous deformation of M-2 and M-4 composites in the first $24 \mathrm{~h}$

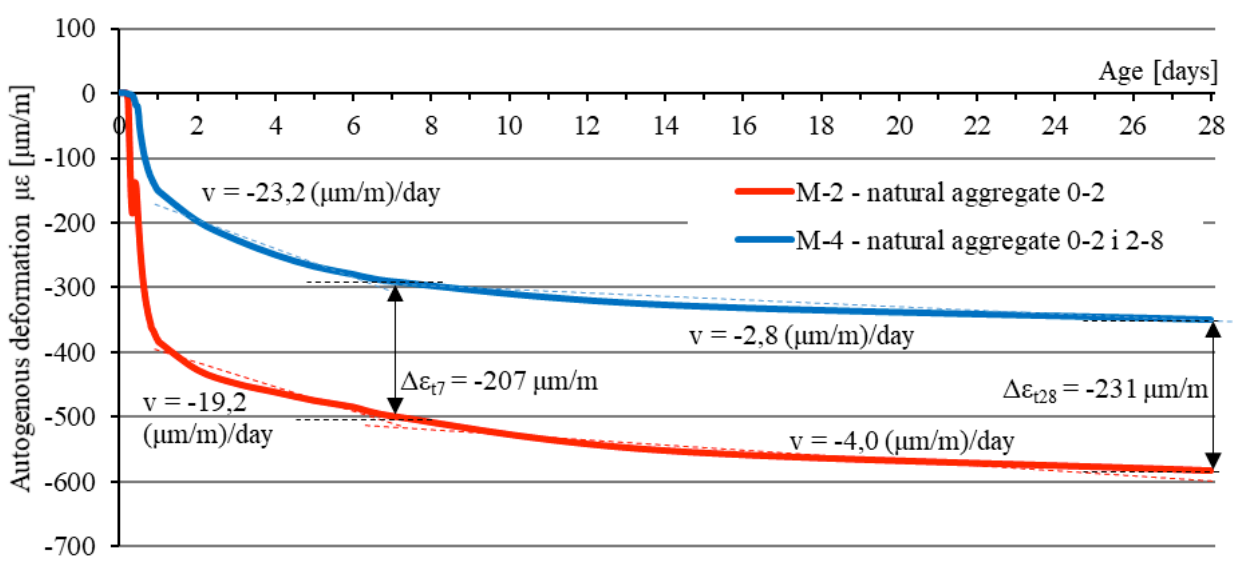

Fig. 9 Autogenous deformation of M-2 and M-4 composites in the first $28 \mathrm{~h}$ 


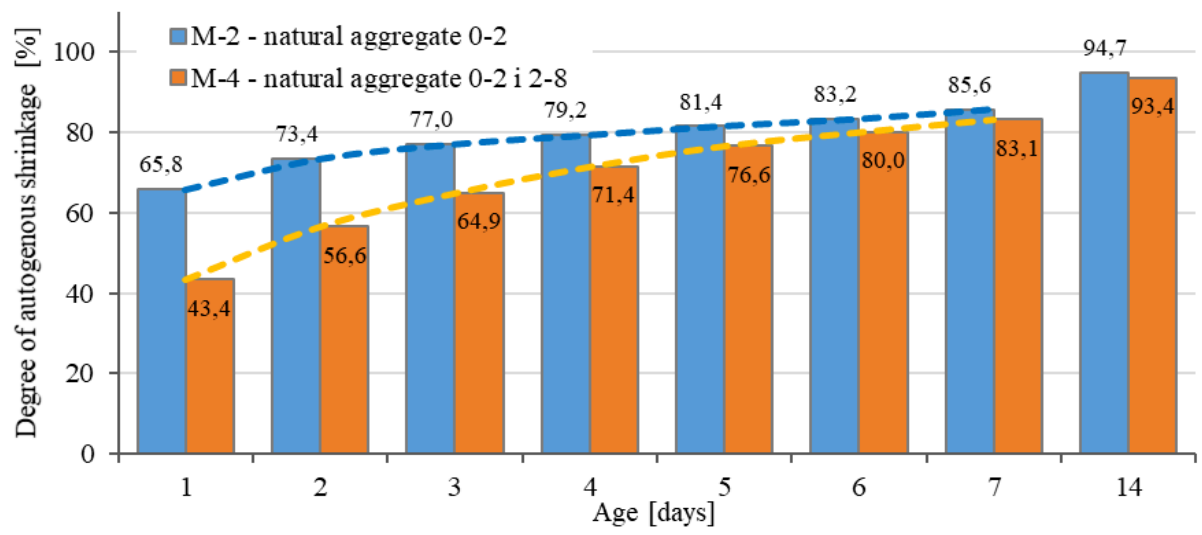

Fig. 10 Daily values of autogenous shrinkage as percentage of the total shrinkage

Following conclusions can be drawn from the aforementioned Figures:

- Increasing the amount of aggregate by replacing the cement in M-4 aggregate decreased the autogenous shrinkage by $60 \%$ after a day, $40 \%$ after 7 days and $40 \%$ after 28 days compared to $\mathrm{M}-2$ composite;

- Increasing the amount of non-deformable aggregate reduces the shrinkage during the first stage of hydration process. It also decreases the development rate of shrinkage by $40 \%$ right after the end of setting time;

- Decreasing the volume of aggregate influenced the development rate of shrinkage. The M-2 concrete exhibited $50 \%$ of the overall shrinkage value after first 24 hours, while M-4 composite reached about $30 \%$. The development of the early age shrinkage is correlated with the chemical reactions during setting. The higher the amount of the cement, the higher the autogenous shrinkage;

- Development rate of the early age shrinkage (from day 1 to 7 ) is higher by about $20 \%$ in composite with higher amount of aggregate. The increase is caused by a higher capillary pressure in the cement matrix. The pressure is increased due to water deficit, higher in M-4 composite. Higher aggregate amount requires higher water demand, which, if not included, might limit the bonding water;

- Similar rates of the shrinkage development are visible in M-2 and M-4 concretes after 7 days of curing. It can be noticed that hardened cement matrix is more resistant to autogenous deformation.

\section{Conclusions}

Performed tests and analysis allowed to draw following conclusions:

- Reduction of the w/c ratio increases the value of autogenous shrinkage and causes it to stabilize faster as the result of less developed network of capillary pores in hardening concrete;

- Composites with lower w/c ratio exhibit intensive and high autogenous shrinkage during setting time, which decreases and stabilizes in the hardening phase;

- Composites with higher w/c ratio exhibit lower shrinkage or swelling in the early stages of setting. During the hardening phase the shrinkage develops at a faster rate than in composites with lower $\mathrm{w} / \mathrm{c}$ ratio;

- Natural aggregate reduces the value and development rate of autogenous shrinkage; 
- Development of autogenous deformation is more intensive in the first 24 hours of concrete curing.

\section{References}

1. P.C. Aïtcin, High Performance Concrete (1998)

2. M. Kaszynska, A. Zielinski, Procedia Engineering 108, 608-615 (2015)

3. M. Kaszynska, A. Zielinski, Brittle Matrix Composites 10, 265-274 (2012)

4. D. Bentz, J. Weiss, Technical Report (2011)

5. K. Kovler, O.M. Jensen, RILEM Report 41 (2007)

6. G. de Schutter, P. Bartos, P. Domone, J. Gibbs, Self-Compacting Concrete (2008) 
